\title{
Aging and the primary cosmetic nasal surgery
}

\author{
H. Shemshadi ${ }^{*}$, R. Sahaf $^{2}$ \\ ${ }^{1}$ Plastic and Reconstructive Surgery, Iranian Research Center on Aging, University of Social Welfare and Rehabilitation Sciences, \\ Tehran, Iran; "Corresponding Author: shemshadii@gmail.com \\ ${ }^{2}$ Iranian Research Center on Aging, University of Social Welfare and Rehabilitation Sciences, Tehran, Iran
}

Received 4 November 2013; revised 5 December 2013; accepted 12 December 2013

Copyright (c) 2014 H. Shemshadi, R. Sahaf. This is an open access article distributed under the Creative Commons Attribution License, which permits unrestricted use, distribution, and reproduction in any medium, provided the original work is properly cited. In accordance of the Creative Commons Attribution License all Copyrights (c) 2014 are reserved for SCIRP and the owner of the intellectual property H. Shemshadi, R. Sahaf. All Copyright (c) 2014 are guarded by law and by SCIRP as a guardian.

\section{ABSTRACT}

Purpose: The main goal of this article is to review the literature of general health and nasal anatomical-physiological profile of the elderly, prior to considering them as a candidate for primary cosmetic rhinoplasty (PCR). Rhinoplasty is the cosmetic nose's surgical alteration. Materials and Methods: We extracted the information from internet search engines and the End Note software version X7. Criteria were applied to the most appropriate clinical messages related to the elderly. We focused on their general health status and their nasal anatomicalphysiological considerations prior to consider them for undergoing PCR. Research links were mostly from the Pub Med and the Medline databases. Results: the literature review showed that as people age, their health status and anatomical-physiological components of their nose alter. Their nasal anatomical supports get weaker, and their nasal internal and external physiology undergoes modifications. Functions related to the nasal supports, normal physiology of smell, airway passage, humidification mechanism and their general appearances are affected by age. Conclusion: Cosmetic surgeons must be aware of the aforementioned changes of the patients' past and present health. Considering performing a complete systemic evaluation and the nasal anatomical-physical examination to assess the degrees of alterations, are crucial pre-operatively.

\section{KEYWORDS}

\section{Elderly; Elderly Cosmetic Surgery; Elderly Rhinoplasty; Elderly Nasal Surgery}

\section{INTRODUCTION}

\subsection{Aging and PCR}

PCR is defined as a type of the cosmetic nasal surgery (rhinoplasty) which the patients undergo for the first time. They consider these surgeries for the main purpose of their beauty and or functional enhancement [1]. The aged individual is referred to the patient over 60 years of age. Females are more likely to seek such operations than the males [2]. Rapid growth of the aging population in the world is an inevitable phenomenon. As this population gets involved in different social activities, he or she is willing to find ways to shape themselves in a better look $[3,4]$. As they become more involve in social networking; they feel the need to present themselves more acceptable physically. In our modern days to look fine, neat and younger is a privilege [5]. Striving to answer all possible alternatives in order to look better and younger, is endeavoured by elderly. Searching an esthetic nasal surgery may be considered as one the possible choices amongst other esthetic alternatives .Restoration of their nose into a better shape, can make them to think of undergoing PCR. Patients who make this decision usually are logical, but in other instances they may not be rational $[5,6]$. Obtaining a thorough health history and extracting their main goals undergoing a PCR is very important. Most elderly want to undergo PCR to promote their physical appearance. They think of becoming more pleasant and younger during their business communications $[7,8]$. If they involve in the politics, they would wish to impress their voters by better and younger look. If they are preachers, they would wish to look more impressive for their followers as a spiritual figure $[8,9]$.

\subsection{Aging and the Nasal Anatomical-Physiological Changes}

As one ages, the anatomical-physiological functions 
diminish. Due to thinning mucous covering inside the nose, their sense of smell, humidification, warming-up and filtering mechanisms get reduced [10]. Also as people age, most of nasal musculoskeletal systems and its anatomical components get weaker. Nasal skin collagen strands get thinner and the subcutaneous fats in these areas get reduced [11]. Skin loosens from its attachments. Muscles get atrophied and weak in their attachments to the ligaments and tendons of the nasal bones and maxilla. Upper part of the nose gets loosened on its attachments to the middle and the caudal zones, which results the nasal airway passage narrowed.

The result of these changes is that the nose relaxes and drops downward [11-13]. This nasal drooping cause more problems in breathing [14]. As the intranasal mucosa coverings get delicate, it will be easily provoked by the allergens and can result more chances of allergic rhinitis attacks $[15,16]$. Polypharmacy and the consequences of multiple medications use in elderly, create alterations in their nasal physiology $[17,18]$. These changes in the nasal anatomy and the physiology, create a dried intranasal zones and potentiate a difficulty in the breathing and the sense of smell [19]. As one ages, more incidences of nasal bleeding are expected by minor trauma [20]. The treatments of their allergic rhinitis get complex [21]. During anesthesia, these changes may reduce the patient`s respiratory system compliance leading to serious respiratory complications during the PCR surgery [22].

\subsection{Selection of an Elderly Patient for PCR}

Peri-operative thoughtfulness in an elderly seeking PCR is extremely significant. The general health status of the elderly is different from young campaigners. Prior to surgery, direct information should be delivered sensitively. Consideration should be exercised in order to evaluate their important underlying health issues before surgery [23]. Any significant systemic disorder which is obtained from the patient`s past and present medical history, affects the cosmetic surgeon's decision in the selection of an elderly who is considering PCR [24]. History of any cardiovascular and or other systemic disease such as diabetic mellitus, hyperlipidemia, osteoarthritis and other diseases, must be reviewed and checked precisely [25]. Their medications used for any types of systemic ailments must be considered. Polypharmacy may influence and interact with anesthetic agents [26]. Some of their medications, may result cognitive impairment and influence their logical decision for undergoing PCR [27]. If the elderly mental health status is not clear, psychiatric consultation is logical to be taken prior to PCR [28-30]. As one ages and the sense of smell is declined, the cosmetic surgeon must clarify that such a function may get worse temporarily or permanently after PCR [31].

\section{METHODOLOGY}

Search engines of Google, Torch, Firefox and the Internet Explore version were used to perform the initial literature review of the topic. Mesh keywords applied to open the related topics. End Note software version X7 was used to collect the pertained research articles with the manuscript. Notes were collected in each section and compiled within the manuscript's text. Written texts were designed as the journal template and checked for writing style with a native English speaker.

\section{RESULTS}

PCR is an option to address an elderly desire to look younger. Individuals are not happy as they age. Different kinds of cosmetic surgeries, notably undergoing a PCR may make them happier. Reaching to all possible desires, in some circumstances are not feasible and in some other instances not logical.

This review of outcome shows the facts of the elderly cosmetic alterations in their nose's anatomy, may not attain their desired outcome and is not always feasible. During their initial consultations with the cosmetic surgeon, all possible limitations must be discussed for a better result. As they be well informed, their expectations and decisions may be based on their nature of the aging process and reconsider their verdict before undergoing a PCR.

\section{DISCUSSION}

Precise evaluations of the health and considering each elderly individually, is highly crucial to gain a reasonable PCR result. General considerations in respect to the anatomical and physiological changes must be discussed seriously. Most underlying diseases in elderly may influence the surgical results. Conversing the gradual nasal changes within the dermis, muscles, tendons as well as all the skeletal systems is needed, before PCR.

\section{CONCLUSION}

Finally, the review focused on the cautions which are needed to be examined by the cosmetic surgeons. Their patient selection must be based on the facts which belong to an individual's aging process. It is recommended that the surgeon must note the patients' subjectivity and objectivity crucial clues in their first visit. Assessments should be based on clear and honest communication while assisting them in their consultation for undergoing a PCR. Such precise notes would determine the surgeon decision in the selection of whom to accept and whom to reject for this operation. Well informed patients with generally acceptable health status, may be a good candidate, while a patient with poor information and weak 
health status, may not be a good candidate to undergo PCR.

\section{ACKNOWLEDGEMENTS}

Hereby thanking Elizabeth Fearon for her excellent guides and English editing of this manuscript. We also appreciate Ms. Zahra Eftekhari for her generous assists in providing office works.

\section{CONFLICT OF INTERESTS}

No conflict of interests exists in this research.

\section{REFERENCES}

[1] Zijlker, T.D. and Quaedvlieg, P.C. (1994) Lateral augmentation of the middle third of the nose with autologous cartilage in nasal valve insufficiency. Rhinology, 32, 3441.

[2] Winkler, A.A. and Downs, B.W. (2008) Aging male rhinoplasty. Facial Plastic Surgery Clinics of North America, 16, 329-335.

[3] Sahin-Yilmaz, A.A. and Corey, J.P. (2007) Rhinitis in the elderly. Clinical Allergy and Immunology, 19, 209-219.

[4] Rohrich, R.J. and Hollier, L.H. (1999) Rhinoplasty with advancing age: Characteristics and management. Otolaryngologic Clinics of North America, 32, 755-773. http://dx.doi.org/10.1016/S0030-6665(05)70168-7

[5] Cochran, C.S., Ducic, Y. and DeFatta, R.J. (2007) Restorative rhinoplasty in the aging patient. The Laryngoscope, 117, 803-807.

http://dx.doi.org/10.1097/01.mlg.0000248240.72296.b9

[6] Rohrich, R.J., Hollier Jr., L.H., Janis, J.E. and Kim, J. (2004) Rhinoplasty with advancing age. Plastic and Reconstructive Surgery, 114, 1936-1944. http://dx.doi.org/10.1097/01.PRS.0000143308.48146.0A

[7] Friedman, O. (2006) Facelift surgery. Facial Plastic Surgery: FPS, 22, 120-128.

[8] Rainsbury, J.W. (2010) The place of rhinoplasty in the ageing face. The Journal of Laryngology and Otology, 124, 115-118. http://dx.doi.org/10.1017/S0022215109990892

[9] Sezgin, B., Findikcioglu, K., Kaya, B., Sibar, S. and Yavuzer, R. (2012) Mirror on the wall: A study of women's perception of facial features as they age. Aesthetic Surgery Journal/The American Society for Aesthetic Plastic Surgery, 32, 421-425.

[10] American Academy of Otolaryngology—Head and Neck Surgery, Milner-Fenwick Inc. (1996) Rhinoplasty [videorecording]. Timonium, Mdu., Milner-Fenwick.

[11] Pacifico, M.D. and Ritz, M. (2010) Correction of senile drooling using the nasolabial sling. Journal of Plastic, Reconstructive \& Aesthetic Surgery: JPRAS, 63, 757-762. http://dx.doi.org/10.1016/j.bjps.2009.01.061

[12] Ries, W.R. and Rathfoot, C.J. (1996) The aging nose in rhinoplasty for facial rejuvenation. Facial Plastic Surgery: FPS, 12, 197-203.
[13] Matros, E., Momoh, A. and Yaremchuk, M.J. (2009) The aging midfacial skeleton: Implications for rejuvenation and reconstruction using implants. Facial Plastic Surgery: FPS, 25, 252-259.

[14] Bom, A.T. and Pinto, A.M. (2009) Allergic respiratory diseases in the elderly. Respiratory Medicine, 103, 16141622. http://dx.doi.org/10.1016/j.rmed.2009.06.003

[15] Bozek, A., Krajewska, J. and Jarzab, J. (2011) Nasal nitric oxide and other diagnostic procedures in seasonal allergic rhinitis: Elderly vs juvenile patients. American Journal of Otolaryngology, 32, 105-108. http://dx.doi.org/10.1016/j.amjoto.2009.11.002

[16] Slavin, R.G. (2010) Special considerations in treatment of allergic rhinitis in the elderly: Role of intranasal corticosteroids. Allergy and Asthma Proceedings: The Official Journal of Regional and State Allergy Societies, 31, 179184.

[17] Yong, T.Y., Lau, S.Y., Li, J.Y., Hakendorf, P. and Thompson C.H. (2012) Medication prescription among elderly patients admitted through an acute assessment unit. Geriatrics \& Gerontology International, 12, 93-101. http://dx.doi.org/10.1111/j.1447-0594.2011.00737.x

[18] Venturini, C.D., Engroff, P., Ely, L.S., Zago, L.F., Schroeter, G., Gomes, I., et al. (2011) Gender differences, polypharmacy, and potential pharmacological interactions in the elderly. Clinics, 66, 1867-1872.

[19] Ventura, M.T., Gelardi, M., D’Amato, A., Buquicchio, R., Tummolo, R., Misciagna, G., et al. (2012) Clinical and cytologic characteristics of allergic rhinitis in elderly patients. Annals of Allergy, Asthma \& Immunology: Official Publication of the American College of Allergy, Asthma, \& Immunology, 108, 141-144.

[20] Grossman, J. and Gates, D. (2010) Mometasone furoate nasal spray for the treatment of elderly patients with perennial allergic rhinitis. Annals of Allergy, Asthma \& Immunology: Official Publication of the American College of Allergy, Asthma, \& Immunology, 104, 452-453.

[21] Busse, P.J. and Kilaru, K. (2009) Complexities of diagnosis and treatment of allergic respiratory disease in the elderly. Drugs \& Aging, 26, 1-22. http://dx.doi.org/10.2165/0002512-200926010-00001

[22] Smith, A.M., Villareal, M., Bernstein, D.I. and Swikert, D.J. (2012) Asthma in the elderly: Risk factors and impact on physical function. Annals of Allergy, Asthma \& Immunology: Official Publication of the American College of Allergy, Asthma, \& Immunology, 108, 305-310.

[23] Shumrick, K.A., Campbell, A. and Becker, F. (1999) Nasal reconstruction in the elderly patient. The case for not letting age determine the method. Archives of Facial Plastic Surgery, 1, 297-301. http://dx.doi.org/10.1001/archfaci.1.4.297

[24] Cronin, J., Livhits, M., Mercado, C., Chen, F., Foster, N, Chandler, C., et al. (2011) Quality improvement pilot program for vulnerable elderly surgical patients. The American Surgeon, 77, 1305-1308.

[25] Gadsby, R., Galloway, M., Barker, P. and Sinclair, A. (2012) Prescribed medicines for elderly frail people with diabetes resident in nursing homes-issues of polyphar- 
macy and medication costs. Diabetic Medicine: A Journal of the British Diabetic Association, 29, 136-139.

[26] Zakrzewski-Jakubiak, H., Doan, J., Lamoureux, P., Singh, D., Turgeon, J. and Tannenbaum, C. (2011) Detection and prevention of drug-drug interactions in the hospitalized elderly: Utility of new cytochrome p450-based software. The American Journal of Geriatric Pharmacotherapy, 9, 461-470. http://dx.doi.org/10.1016/j.amjopharm.2011.09.006

[27] Wehling, M. (2012) Medication in the elderly: Cognitive impairment by drugs. Internist (Berlin), 53, 1240-1247.

[28] Walder, A. and Greil, W. (2011) Adverse effects of treatment with psychotropic drugs in the elderly-Special risks, protective mechanisms, prognosis. Praxis, 100, 15291532. http://dx.doi.org/10.1024/1661-8157/a000749

[29] Catic, A.G. (2011) Identification and management of in-hospital drug-induced delirium in older patients. Drugs \& Aging, 28, 737-748. http://dx.doi.org/10.2165/11592240-000000000-00000

[30] Liu, C.L., Peng, L.N., Chen, Y.T., Lin, M.H., Liu, L.K. and Chen, L.K. (2012) Potentially inappropriate prescribing (IP) for elderly medical inpatients in Taiwan: A hospital-based study. Archives of Gerontology and Geriatrics, 55, 148-151. http://dx.doi.org/10.1016/j.archger.2011.07.001

[31] Shemshadi, H., Azimian, M., Onsori, M.A. and Azizabadi Farahani, M. (2008) Olfactory function following open rhinoplasty: A 6-month follow-up study. BMC Ear, Nose, and Throat Disorders, 8, 6.

http://dx.doi.org/10.1186/1472-6815-8-6 